\title{
Molecular-Scale Hybrid Membranes Derived from Metal-Organic Polyhedra for Gas Separation
}

\author{
Xinlei Liu, ${ }^{*}{ }^{\dagger}$ (৫) Xuerui Wang, ${ }^{\dagger}$ Anastasiya V. Bavykina, ${ }^{\S}$ Liangyong Chu, ${ }^{\ddagger \oplus}$ Meixia Shan, \\ Anahid Sabetghadam, ${ }^{\dagger}$ Hozanna Miro, ${ }^{\|}$Freek Kapteijn, ${ }^{\dagger}{ }^{\circ}$ and Jorge Gascon ${ }^{*}, \dagger, \S_{\odot}$
}

${ }^{\dagger}$ Catalysis Engineering, Department of Chemical Engineering and ${ }^{\ddagger}$ Organic Materials \& Interface, Department of Chemical Engineering, Delft University of Technology, Van der Maasweg 9, 2629 HZ Delft, The Netherlands

${ }^{\S}$ King Abdullah University of Science and Technology, KAUST Catalysis Center, Advanced Catalytic Materials, Thuwal 23955, Saudi Arabia

"Kavli Institute of Nanoscience, Delft University of Technology, Lorentzweg 1, 2628 CJ Delft, The Netherlands

Supporting Information

ABSTRACT: The preparation and the performance of mixed matrix membranes based on metal-organic polyhedra (MOPs) are reported. MOP fillers can be dispersed as discrete molecular units (average $9 \mathrm{~nm}$ in diameter) when low filler cargos are used. In spite of the low doping amount (1.6 wt \%), a large performance enhancement in permeability, aging resistance, and selectivity can be achieved. We rationalize this effect on the basis of the large surface to volume ratio of the filler, which leads to excellent dispersion at low concentrations and thus alters polymer packing. Although membranes based only on the polymer component age quickly with time, the performance of the resulting MOP-containing membranes meets the commercial target for postcombustion $\mathrm{CO}_{2}$ capture for more than 100 days.
Metal-organic polyhedra hybrid membranes

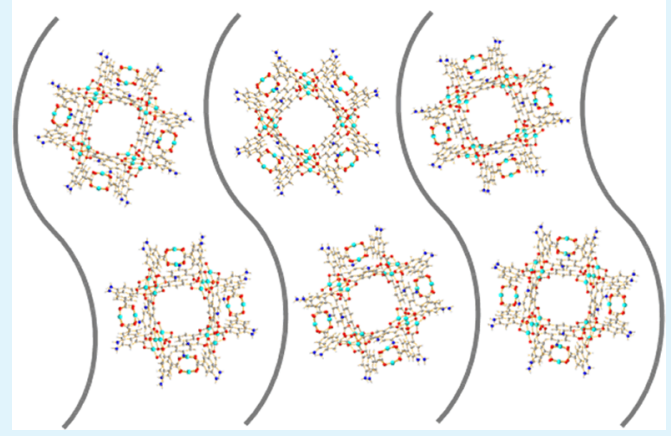

KEYWORDS: hybrid membrane, gas separation, metal-organic polyhedron, molecular scale, cage

\section{INTRODUCTION}

The use of composites in membrane separation is attracting a great deal of attention. ${ }^{1-3}$ By using two components with different transport properties in one single membrane, such composites have the potential to offer the easy processability of polymers and the superior performance of the filler. ${ }^{4}$ Various additives, e.g., silica, ${ }^{3}$ zeolites, ${ }^{5}$ metal-organic frameworks (MOFs) ${ }^{6-9}$ and porous organic frameworks, ${ }^{10-12}$ have been employed in combination with a large variety of polymers. MOFs are promising fillers to construct composite membranes in light of their rich chemistry (expected compatibility) and transport properties. ${ }^{2,13}$ However, the final performance of the membrane is determined by several additional factors of the fillers, e.g., surface functional groups, ${ }^{14,15}$ aspect ratio, ${ }^{16}$ and particle size. ${ }^{7,17-19}$ The particle size of the fillers is one of these critical properties. For instance, separation performance of mixed matrix membranes (MMMs) based on MOF nanoparticles is usually superior to that of membranes prepared with bigger particles of the same filler. ${ }^{717-19}$ This is because smaller particles inherently expose larger external surface areas to interact with the polymer, improving in this way compatibility. $7,17-19$

Metal-organic polyhedra (MOPs) $)^{20-23}$ are considered as discrete porous cage-like MOF analogues. ${ }^{24}$ The particle size of individual MOP cages is normally in the range of $2.5-5.0 \mathrm{~nm}$. Moreover, most MOPs are soluble (or dispersible) in a wide variety of solvents. These properties provide important advantages to construct hybrid membranes. In the past few years, a few MOP composite membranes have been reported, ${ }^{25-28}$ along with analogous membranes with porous organic cages (POCs) as fillers. ${ }^{29,30}$ Surprisingly, in these cases, a large cargo of filler was used (normally more than $10 \mathrm{wt} \%$ of MOP or POC), leading to possible agglomeration and hiding the effect of fillers.

Here, we take advantage of the small size of individual MOP units and demonstrate that the best membrane performance is achieved at a very low MOP loading (1.6 wt \%). Under these conditions, well-dispersed MOPs are incorporated in the membrane rather than agglomerates, resulting in large separation performance enhancements, including improvements in permeability, selectivity, and aging resistance while maintaining the unmatched processability of the polymer phase.

\section{EXPERIMENTAL SECTION}

Preparation of MOP-15. MOP-15 was synthesized according to the recipe reported by Yaghi et al. ${ }^{31}$ Fresh glycine tert-butyl ester hydrochloride $(0.242 \mathrm{~g}$ ) (Sigma-Aldrich, $\geq 99.0 \%$ ) was dissolved in 6.0 $\mathrm{mL}$ of $\mathrm{N}, \mathrm{N}$-dimethylformamide (DMF, Acros, $99.8 \%$, Extra Dry).

Received: April 30, 2018

Accepted: June 5, 2018

Published: June 5, 2018 
Then, $0.22 \mathrm{~mL}$ of triethylamine (Sigma-Aldrich, $\geq 99 \%$ ) was added to the solution, and white precipitate was formed and removed by filtration. The filtrate was mixed with $0.144 \mathrm{~g}$ of copper acetate monohydrate $\left(\mathrm{Cu}(\mathrm{OAc})_{2} \cdot \mathrm{H}_{2} \mathrm{O}\right.$, Sigma-Aldrich, 99.99\%) in DMF $(6.0$ $\mathrm{mL})$ and labeled as solution I. 5-Aminoisophthalic acid $(0.0018 \mathrm{~g})$ $\left(\mathrm{H}_{2}\right.$ 5- $\mathrm{NH}_{2}-\mathrm{mBDC}$, Merck, $\left.\geq 98.0 \%\right)$ was dissolved in a DMF (2.6 $\mathrm{mL}) / \mathrm{EtOH}$ (0.4 mL, Acros, 99.5\%, Extra Dry) solution and labeled as solution II. Solution II was mixed with $3.0 \mathrm{~mL}$ of solution I in a capped vial and maintained at ambient condition for 5 days. Green truncatedoctahedral crystals were harvested. After rinsing with DMF $(3 \times 10$ $\mathrm{mL}$ ), the crystals were stored in DMF for later use.

Preparation of Membranes. MOP-15 $(0.016 \mathrm{~g})$ was dissolved in $10 \mathrm{~mL}$ of dimethyl sulfoxide (DMSO, Sigma-Aldrich, $\geq 99.0 \%$ ), and transparent green solution was formed. 4, $4^{\prime}$ (Hexafluoroisopropylidene)diphthalic anhydride-diaminomesitylene $(6 \mathrm{FDA}-\mathrm{DAM})(0.10 \mathrm{~g})\left(M_{\mathrm{w}} \sim 272000 \mathrm{Da}\right.$, Akron) dissolved in $9.0 \mathrm{~mL}$ of DMSO was mixed with $1.0 \mathrm{~mL}$ of MOP-15 solution via stirring overnight. The homogeneous light green solution was transferred to a glass Petri-dish and dried at $373 \mathrm{~K}$ for $12 \mathrm{~h}$ (in a solvent saturated atmosphere) to slowly evaporate the solvent. Finally, the free-standing film was peeled off and dried at $353 \mathrm{~K}(24 \mathrm{~h})$ and $423 \mathrm{~K}(20 \mathrm{~h})$ under vacuum. Neat 6FDA-DAM and MOP-15/ 6FDA-DAM membranes with various filler loadings were prepared by the identical approach via modulating the volume ratio of the served MOP-15 and 6FDA-DAM solutions. Polymer 6FDA-DAM was degassed overnight at $423 \mathrm{~K}$ under vacuum before use. The thickness of all of the membranes is around $20-30 \mu \mathrm{m}$, according to the values measured with a digital micrometer (Mitutoyo) at different locations within each membrane and then averaged.

Characterizations. Microscope image was captured from a Microscope BRESSER under ambient condition. The sample was prepared by dropping MOP-15 DMF solution on a glass slide without drying. A Bruker-D8 Advance diffractometer (using Co $\mathrm{K} \alpha$ radiation, $\lambda$ $=0.179 \mathrm{~nm}$ at $35 \mathrm{kV}$ and $40 \mathrm{~mA}$ ) was employed to analyze the crystalline structure of powders and membranes. UV-vis spectra of the MOP-15/DMSO solution were collected on the UNICAM UV 500 spectrometer in the wavelength range of $190-900 \mathrm{~nm} . \mathrm{CO}_{2}(298$ $\mathrm{K})$ and $\mathrm{N}_{2}(77 \mathrm{k})$ adsorption isotherms of the samples were performed in a Tristar II 3020 (Micromeritics) setup. Prior to the measurements, the samples were degassed at $353 \mathrm{~K}$ under vacuum for $16 \mathrm{~h}$.

Atomic force microscopy (AFM) micrographs were collected in a noncontact tapping mode using a Solver NEXT AFM instrument from NT-MDT. Gold-coated cantilevers (NSG 03, from NT-MDT) with spring constants ranging from 0.4 to $2.7 \mathrm{~N} \mathrm{~m}^{-1}$ (resonant frequency of $90 \mathrm{kHz}$ ) were used and calibrated by the thermal noise method. The tip diameter of probe is around $20 \mathrm{~nm}$. Nova Px 3.2.5 software was used for all of the data acquisition and analysis. To capture the images, a sample of MOP-15 was prepared by spin coating a dilute MOP-15/ DMSO solution $\left(10 \mu \mathrm{g} \mathrm{mL}^{-1}\right)$ on a silicon wafer and dried under vacuum at room temperature. The silicon wafer was pretreated with acetone and oxygen plasma (at a pressure of $2.1 \mathrm{mbar}$ for $1 \mathrm{~min}$, using a Harrick plasma cleaner, from Anadis Instruments) for cleaning.

Scanning electron microscopy (SEM) images of the membranes were acquired using a JEOL 6010 microscope. The specimen was prepared by cryo-fracturing in liquid $\mathrm{N}_{2}$ and coated with gold. Focused ion beam scanning electron microscopy (FIB-SEM) experiments were performed in an FEI Helios G4 CX microscope. A conductive thin layer of $\mathrm{Au}(0.1 \mu \mathrm{m}$ thickness $)$ and a protective thin layer of $\mathrm{Pt}(0.3$ $\mu \mathrm{m}$ thickness) were deposited on the surface of specimen using the sputter coater and the gas injection system, respectively. Slices with a nominal thickness of $2 \mu \mathrm{m}$ were milled away by the FIB, operating at $30 \mathrm{kV}$ and $80 \mathrm{pA}$. Two individual SEM micrographs of the membrane cross section exposed on each milling were recorded, with an in-lens secondary electron detector operated at $10 \mathrm{kV}$. To calculate the average filler size using SEM images, around 70 filler particles were identified and measured by ImageJ software.

Diffuse reflectance infrared Fourier transform (DRIFT) spectra were acquired in a Nicolet 8700 FT-IR (Thermo Scientific) spectrometer. The samples were dried overnight at $423 \mathrm{~K}$ under vacuum before recording data. Thermogravimetric analysis (TGA) of
MOP-15 was performed on a Mettler Toledo TGA/SDTA851e apparatus under $\mathrm{N}_{2}$ flow $\left(100 \mathrm{~mL} \mathrm{~min}^{-1}\right)$ from 303 to $1073 \mathrm{~K}$ with a ramp speed of $5 \mathrm{~K} \mathrm{~min}^{-1}$.

Gas Permeation. The $\mathrm{CO}_{2} / \mathrm{N}_{2}$ separation performance was evaluated in a home-made setup described elsewhere. ${ }^{16}$ The membranes, with a diameter of $1.8 \mathrm{~cm}$ and an effective area of 1.3 $\mathrm{cm}^{2}$, were cut from the as-synthesized films and mounted in a flange between two Viton O-rings. A macroporous stainless steel disc (316L, $20 \mu \mathrm{m}$ nominal pore size) was used as support. The permeation module was placed inside a convection oven, where the temperature was set to $298 \mathrm{~K}$. A flow of $\mathrm{CO}_{2}(15 \mathrm{~mol} \%)$ and $\mathrm{N}_{2}(85 \mathrm{~mol} \%)$ mixture $\left(133 \mathrm{~mL} \mathrm{~min}^{-1}\right.$, standard temperature and pressure (STP)) was applied as feed and helium $\left(5 \mathrm{~mL} \mathrm{~min}{ }^{-1}, \mathrm{STP}\right)$ as a sweep gas. The feed pressure was adjusted in the range of $1-4$ bar absolute using a back-pressure controller at the retentate side, whereas the permeate side was kept at atmospheric pressure (1 bar absolute) for all measurements. The permeation results of the membranes were recorded after steady state was confirmed using consecutive online gas chromatography (GC) analyses (Interscience Compact GC). Gas separation performance is defined by the gas permeability $(P)$ of the individual components and selectivity $(\alpha)$. The permeability for the component $i\left(P_{i}\right)$ was calculated as follows (eq 1)

$$
P_{i}=\frac{F_{i} \times l}{\Delta p_{i} \times A}
$$

where $F_{i}$ denotes the molar flow rate of compound $i, l$ is the thickness of the membrane, $\Delta p_{i}$ is the partial pressure difference of $i$ across the membrane, and $A$ is the membrane area. The unit of $P_{i}$ adopts Barrer, where 1 Barrer $=3.35 \times 10^{-16} \mathrm{~mol} \mathrm{~m} \mathrm{~m}^{-2} \mathrm{~s}^{-1} \mathrm{~Pa}^{-1}$.

The mixed gas selectivity $(\alpha)$ of $\mathrm{CO}_{2}$ over $\mathrm{N}_{2}$ is defined as the ratio of their permeabilities (eq 2)

$$
\alpha=\frac{P_{\mathrm{CO}_{2}}}{P_{\mathrm{N}_{2}}}
$$

The Maxwell model is quite useful for understanding the effective permeability and structure of mixed matrix membranes. ${ }^{2,3,5}$ The model was initially developed by Maxwell to estimate the dielectric properties of heterogeneous media. ${ }^{32}$ Membrane scientists used this model to predict molecular permeation of mixed matrix membranes (eq 3$)^{33}$ under a pressure-driving force because it is analogous to the conduction of a dielectric in heterogeneous media under an electric potential

$$
P_{\text {eff }}=P_{\mathrm{c}}\left[\frac{P_{\mathrm{d}}+2 P_{\mathrm{c}}-2 \varnothing_{\mathrm{d}}\left(P_{\mathrm{c}}-P_{\mathrm{d}}\right)}{P_{\mathrm{d}}+2 P_{\mathrm{c}}+\varnothing_{\mathrm{d}}\left(P_{\mathrm{c}}-P_{\mathrm{d}}\right)}\right]
$$

where $P_{\text {eff }}$ is the effective permeability of the mixed matrix membrane, $\varnothing_{\mathrm{d}}$ is the volume fraction of filler (dispersed phase), $P_{\mathrm{c}}$ and $P_{\mathrm{d}}$ represent the permeability of the continuous phase (polymer) and dispersed phase (MOPs here), respectively. In this study, to maximize the predicted $P_{\text {eff, }}$ an ultrahigh permeability of $P_{\mathrm{d}}$ (relative to $P_{\mathrm{c}}$ ) is adopted by assuming the transport of the penetrant in MOPs is ultrafast. So, the above equation is transformed to the following one to predict the permeability of hybrid membranes

$$
P_{\text {eff }}=P_{\mathrm{c}}\left(\frac{1+2 \varnothing_{\mathrm{d}}}{1-\varnothing_{\mathrm{d}}}\right)
$$

$\varnothing_{\mathrm{d}}$ is calculated based on the corresponding mass loading of fillers and material density. The required particle loading $\left(\varnothing_{\mathrm{d}}^{\prime}\right.$, vol \%), which could provide equal external surface area, with varied filler size $\left(r^{\prime}\right.$, diameter, $\mathrm{nm}$ ), was calculated employing eq 5

$$
\varnothing_{\mathrm{d}}^{\prime}=\left(\frac{r^{\prime}}{r^{0}}\right) \varnothing_{\mathrm{d}}^{0}
$$

The morphology of the filler was assumed as sphere. The optimal MOP particle loading $\left(\varnothing_{\mathrm{d}}^{0}=1.8 \mathrm{vol} \%\right)$ and the related average MOP diameter $\left(r^{0}=9 \mathrm{~nm}\right)$ were adopted. 

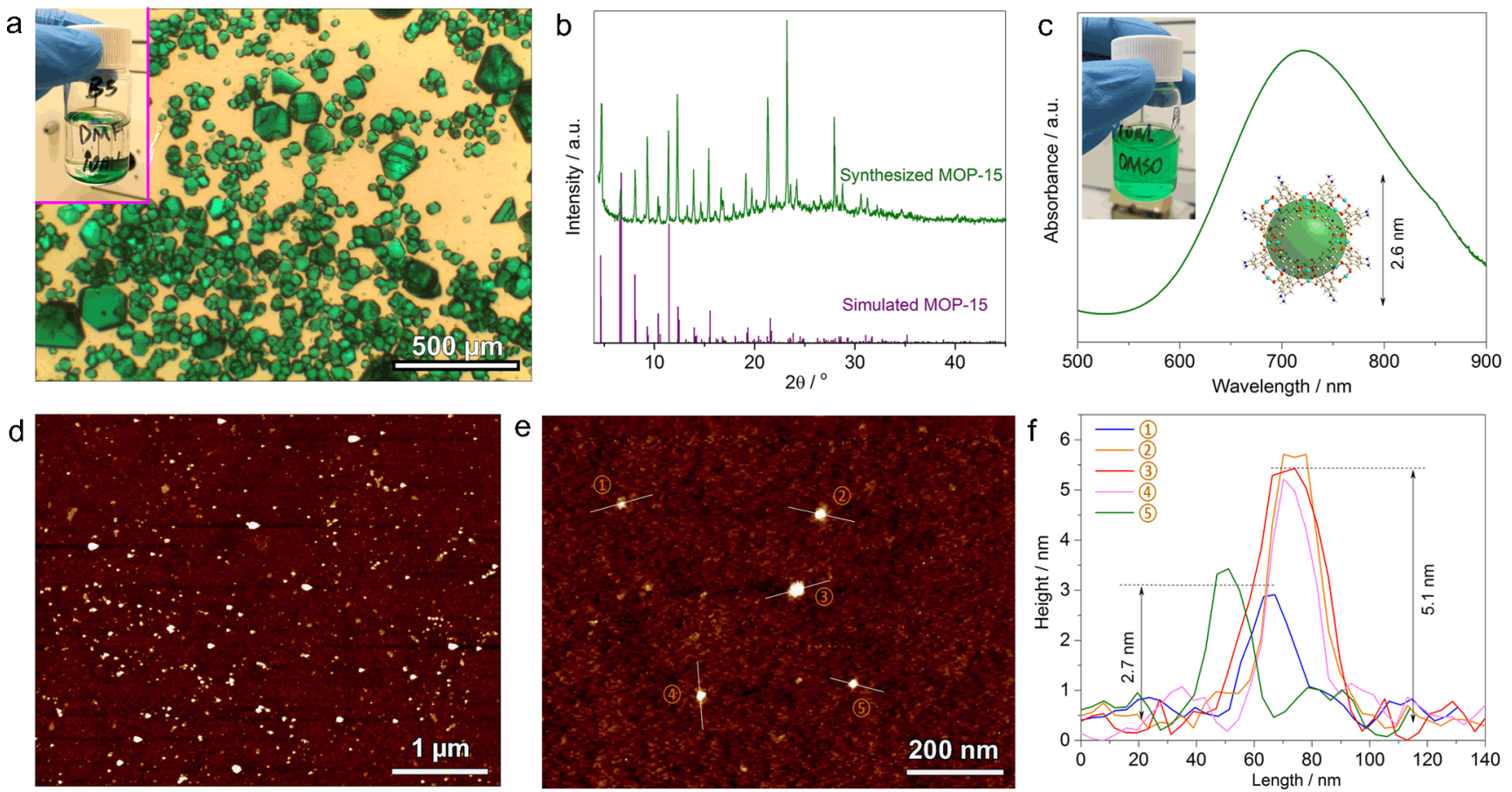

Figure 1. (a) Microscope image of the as-synthesized MOP-15 crystals. The inset is a photo of the MOP-15 crystals precipitated in DMF solution; (b) XRD pattern of the as-synthesized MOP-15. The simulated XRD is shown for reference. (c) Absorption spectra of MOP-15 in DMSO solution. The insets are a photo of MOP-15 dissolved in DMSO solution and a unit cage structure of MOP-15; AFM height images ((d) low magnification and (e) high magnification) and corresponding height profiles (f) of MOP-15 particles on top of a silicon wafer along the white lines marked in image (e).

\section{RESULTS AND DISCUSSION}

Metal-Organic Polyhedra. MOP- $15^{31}$ with a formula $\mathrm{Cu}_{24}\left(\mathrm{NH}_{2}\right.$-mBDC) (5-amino-1,3-benzenedicarboxylate) ${ }_{24}$ (solvents omitted) was selected as filler. The amino groups on its framework are expected to engage in hydrogen bonding with the polyimide matrices according to our previous research on MOF mixed matrix membranes. ${ }^{7,8}$ This discrete molecular cage is constructed from 12 copper paddle-wheel clusters bridged by $24 \mathrm{NH}_{2}$-mBDC linkers (Figure S1). ${ }^{31}$ The cage is porous with an average size of ca. $2.6 \mathrm{~nm}$, a cavity diameter of ca. 1.5 $\mathrm{nm}$, and aperture diameters of around $0.6 \mathrm{~nm}$ (triangular windows) and $0.9 \mathrm{~nm}$ (square windows), as estimated from crystallographic data. ${ }^{31}$

On the basis of the synthesis reported by Yaghi et al., ${ }^{31}$ green truncated-octahedral crystals (Figure 1a) of MOP-15 were successfully prepared as confirmed by powder X-ray diffraction (XRD) analysis (Figure 1b). The crystals are soluble in DMSO, forming a transparent green solution with an intense absorbance around $720 \mathrm{~nm}$, assigned to the copper paddlewheel units (Figure 1c). ${ }^{23}$

After solvent evaporation, MOP-15 crystallizes into aggregates (Figure 1d,e). Individual MOP-15 cages with an average height of $2.7 \mathrm{~nm}$ were identified based on the corresponding AFM height profiles (Figure 1f), consistent with the value (2.6 $\mathrm{nm}$, Figure 1c) calculated from crystallographic data. The particles visualized with an average height of $5.1 \mathrm{~nm}$ (Figure $1 \mathrm{e}, \mathrm{f})$ probably result from the stacking of two MOP-15 cages.

The thermogravimetric analysis (Figure 2a) indicates that MOP-15 has a good thermal stability (up to $515 \mathrm{~K}$ ). The assynthesized aggregated MOP-15 particles possess a low surface area (Brunauer-Emmett-Teller $17.5 \mathrm{~m}^{2} \mathrm{~g}^{-1}$, Figure $2 \mathrm{~b}$ ) with a $\mathrm{CO}_{2}$ uptake of $0.7 \mathrm{mmol} \mathrm{g}^{-1}$ at $1.2 \mathrm{bar}$ and $298 \mathrm{~K}$ (Figure 2c).
Formation and Characterization of Membranes. By dissolving both MOP-15 and 6FDA-DAM polymers in DMSO, stable, transparent (light green) solutions were formed. To fabricate homogeneous hybrid membranes, preliminary experiments were carried out to determine the temperature and drying rate for solvent evaporation. A temperature of $373 \mathrm{~K}$ and the controlled drying rate (for $12 \mathrm{~h}$ in a solvent saturated atmosphere) were finally selected as optimized conditions (see Experimental Section for details). Lower temperature and slower drying rate resulted in particle agglomeration. This is in essence because the solubility of MOPs increases with temperature $^{22}$ and a fast drying rate could possibly fix MOPs among the polymer chains before aggregation happens. However, attempts to further increase the temperature and drying rate lead to the formation of defects in the continuous polymer phase (Figure S2). These observations highlight the importance of well-controlled conditions during membrane drying. The structural integrity of MOP-15 $\left(\mathrm{NH}_{2}\right.$ stretching vibration $\left(3300 \mathrm{~cm}^{-1}\right)$ from aromatic amines and $\mathrm{C}=\mathrm{O}$ stretching vibration $\left(1600 \mathrm{~cm}^{-1}\right)$ from carboxylate moieties) and 6FDA-DAM in the hybrid membrane was verified by DRIFT analysis (Figure 2d).

The morphology of neat and hybrid 6FDA-DAM membranes was characterized by SEM (Figure 3). At a low particle loading (1.6 wt \%), no visible MOP-15 fillers were observed (Figure $3 c, d$ ), whereas pronounced cage agglomeration appeared at higher concentration of MOP-15 (7.4 wt \%) (Figure $3 \mathrm{e}, \mathrm{f}$ ). Consequently, microcracks between the filler and polymer phases were generated. To further investigate MOP distribution in the hybrid membrane at low particle loading, focused ion beam scanning electron microscopy (FIB-SEM) (Figure $4 a-e 2$ ) with relatively high magnification was employed. Hereafter, unless otherwise stated, the default 

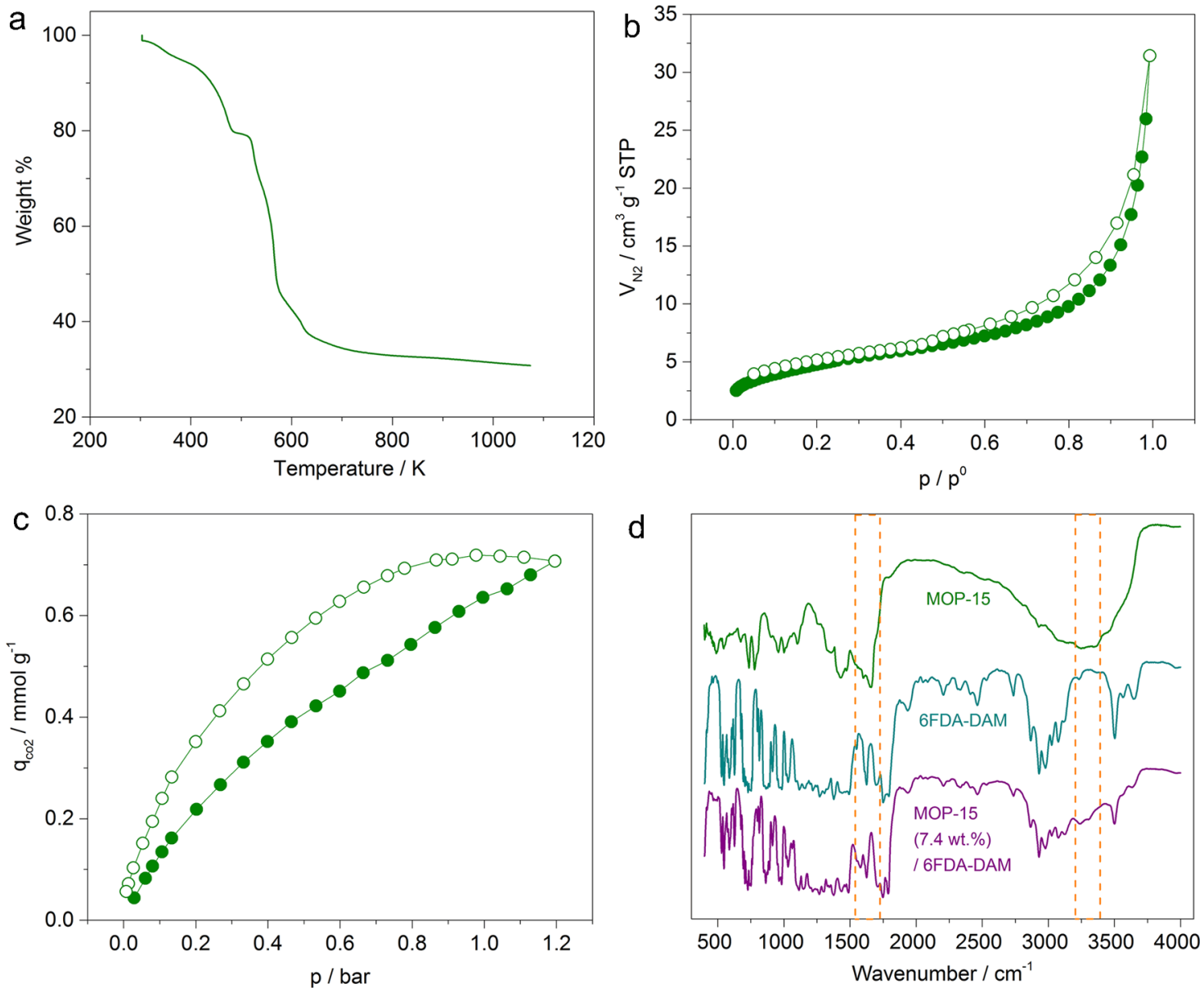

Figure 2. a) TG profile of MOP-15. (b) $\mathrm{N}_{2}\left(77 \mathrm{~K}\right.$ ) and (c) $\mathrm{CO}_{2}(298 \mathrm{~K})$ adsorption (solid symbols) and desorption (open symbols) isotherms. (d) DRIFT spectra of MOP-15, 6FDA-DAM, and MOP-15 (7.4 wt \%)/6FDA-DAM.
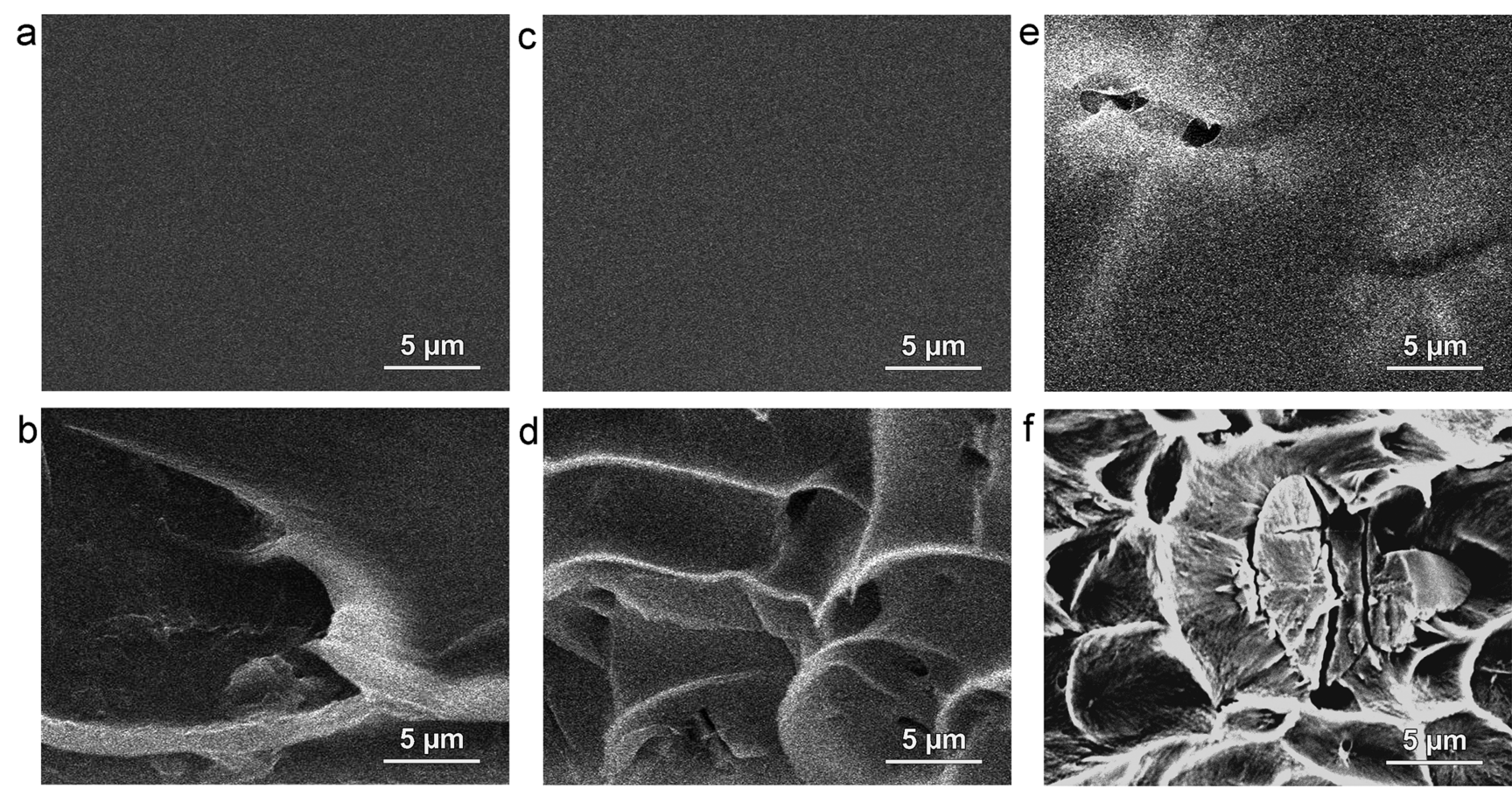

Figure 3. SEM surface (a, c, e) and cross-sectional (b, d, f) images of neat 6FDA-DAM (a, b), MOP-15 (1.6 wt \%)/6FDA-DAM (c, d), and MOP15 (7.4 wt \%)/6FDA-DAM (e, f) membranes. 

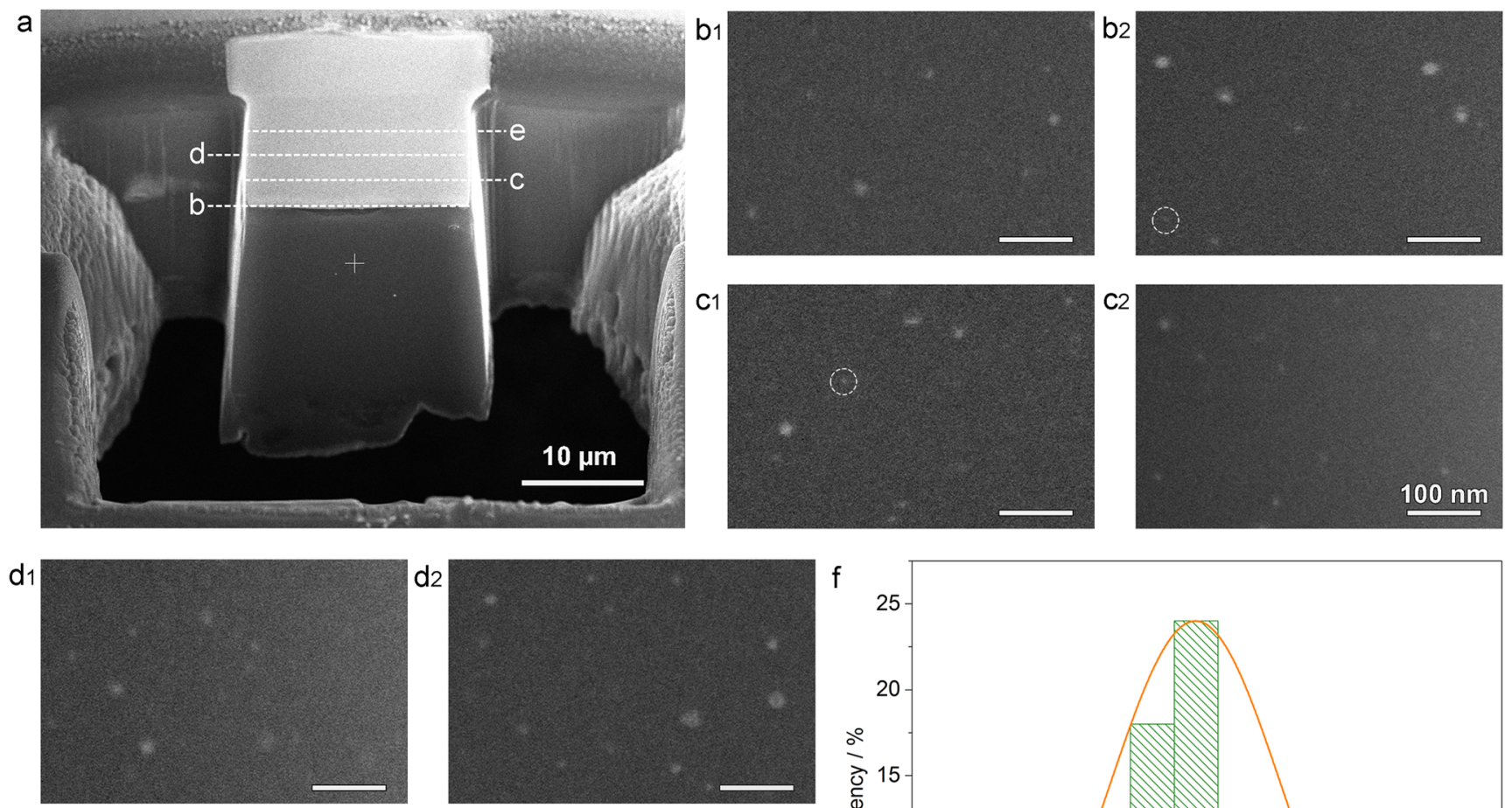

e1

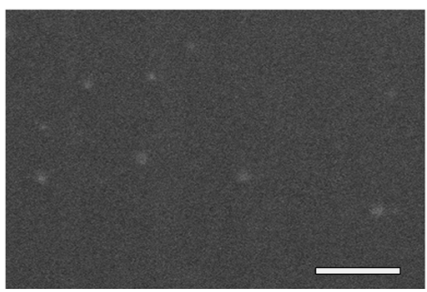

e2

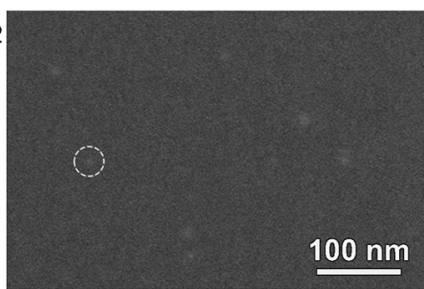

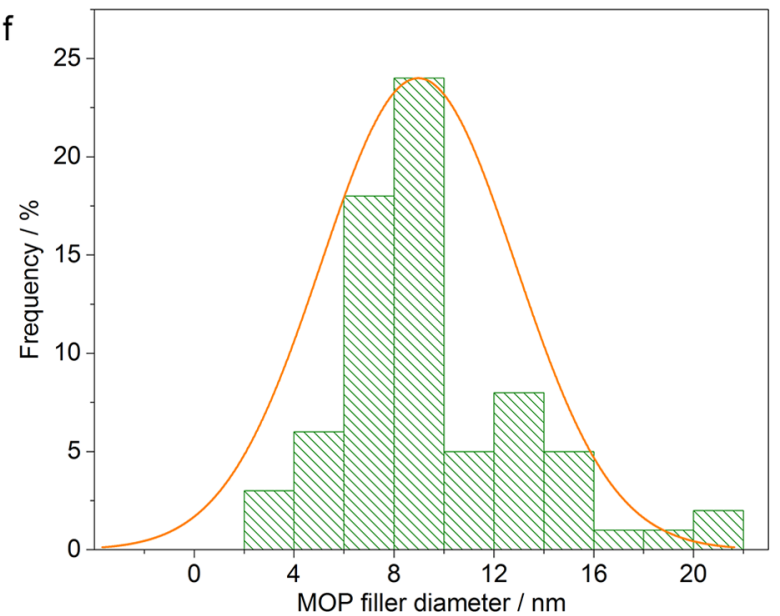

Figure 4. Cross-sectional FIB-SEM images of MOP-15/6FDA-DAM membrane (a-e). Two individual images (numbered as 1 and 2) exposed on each milling (marked in (a)) were recorded. Fillers with a diameter around 2-3 $\mathrm{nm}$ are highlighted with dashed circles; (f) particle size distribution of MOP-15 fillers in the hybrid membrane. Around 70 filler particles were identified from (b1) to (e2), and the diameters were measured by ImageJ software. The filler loading is $1.6 \mathrm{wt} \%$.

particle loading of MOP-15/6FDA-DAM hybrid membrane is 1.6 wt \% (i.e., 1.8 vol \%). Very homogeneous membranes with particles embedded in the polymer matrix were found (Figure $4 \mathrm{~b} 1-\mathrm{e} 2)$. As anticipated, no detectable gaps between the filler and the matrix could be observed, illustrating an intimate adhesion between both phases. Individual MOP cages with a size around 2-3 $\mathrm{nm}$ can be recognized (highlighted in white circles) along with bigger particles resulting from agglomeration. On the basis of particle size distribution analysis (Figure $4 \mathrm{f})$, the average filler size is around $9 \mathrm{~nm}$.

The microstructure of the membranes was studied by XRD. As depicted in Figure 5a, the neat 6FDA-DAM membrane exhibits one broad diffraction peak centered at $15.9^{\circ}$ (corresponding to a $d$-spacing of $0.64 \mathrm{~nm}$ ), together with a relatively weak peak at $6.7^{\circ}$ (corresponding to a $d$-spacing of $1.53 \mathrm{~nm})$. In the case of the hybrid membrane, after the cages rearranged, no diffraction peaks from the original MOP-15 crystals (Figure 5a) were found. In contrast, the reflections from the parent polymer shift to lower angles (15.3 and 6.4 $4^{\circ}$ ), indicating the stabilization of polymer chains at higher $d$ spacing values $(0.67$ and $1.60 \mathrm{~nm})$. We speculate that this is due to disruption of the polymer chains as a result of addition of such small filler particles. Not surprisingly, when agglomeration of the MOP into bigger units occurs (membranes with a $7.4 \mathrm{wt} \%$ MOP loading), no change in the diffractogram is observed (Figure $5 b$ ).

Gas Separation Performance. After implanting MOP fillers, the $\mathrm{CO}_{2}$ adsorption uptake of the membrane was well maintained (Figure S3). The lower $\mathrm{CO}_{2}$ uptake of MOP-15 is responsible for the slight decline of $\mathrm{CO}_{2}$ adsorption on the hybrid membrane. The membrane performance was evaluated by separating $\mathrm{CO}_{2}$ from $\mathrm{N}_{2}$ at $298 \mathrm{~K}$ (Figure 6) under conditions relevant to postcombustion $\mathrm{CO}_{2}$ capture (15 mol \% $\mathrm{CO}_{2}$ and $85 \mathrm{~mol} \% \mathrm{~N}_{2}$ ). The neat 6FDA-DAM membranes prepared following exactly the same drying conditions as in the case of the MMMs exhibit a $\mathrm{CO}_{2}$ permeability of 1010 Barrer with a $\mathrm{CO}_{2} / \mathrm{N}_{2}$ selectivity of 23.9 under 1 bar absolute feed pressure (Figure 6a). This permeability was slightly higher than that in our previous publications ${ }^{34,35}$ and dropped to a comparable value after aging (vide infra). By doping $1.6 \mathrm{wt} \%$ MOP-15, an increase in $\mathrm{CO}_{2}$ permeability (40\%, to 1413 Barrer) along with a modest improvement in selectivity (26.7) was observed. With a further increase of particle loading to 3.2 wt \%, no improvement in $\mathrm{CO}_{2}$ permeability or selectivity occurred. We attribute this effect to the agglomeration of MOP15. Indeed, further increase in filler concentration (7.4 wt \%) leads to a dramatic increase in $\mathrm{CO}_{2}$ permeability at the expense of selectivity as a consequence of further filler agglomeration and the formation of defects (Figure 3e,f). 

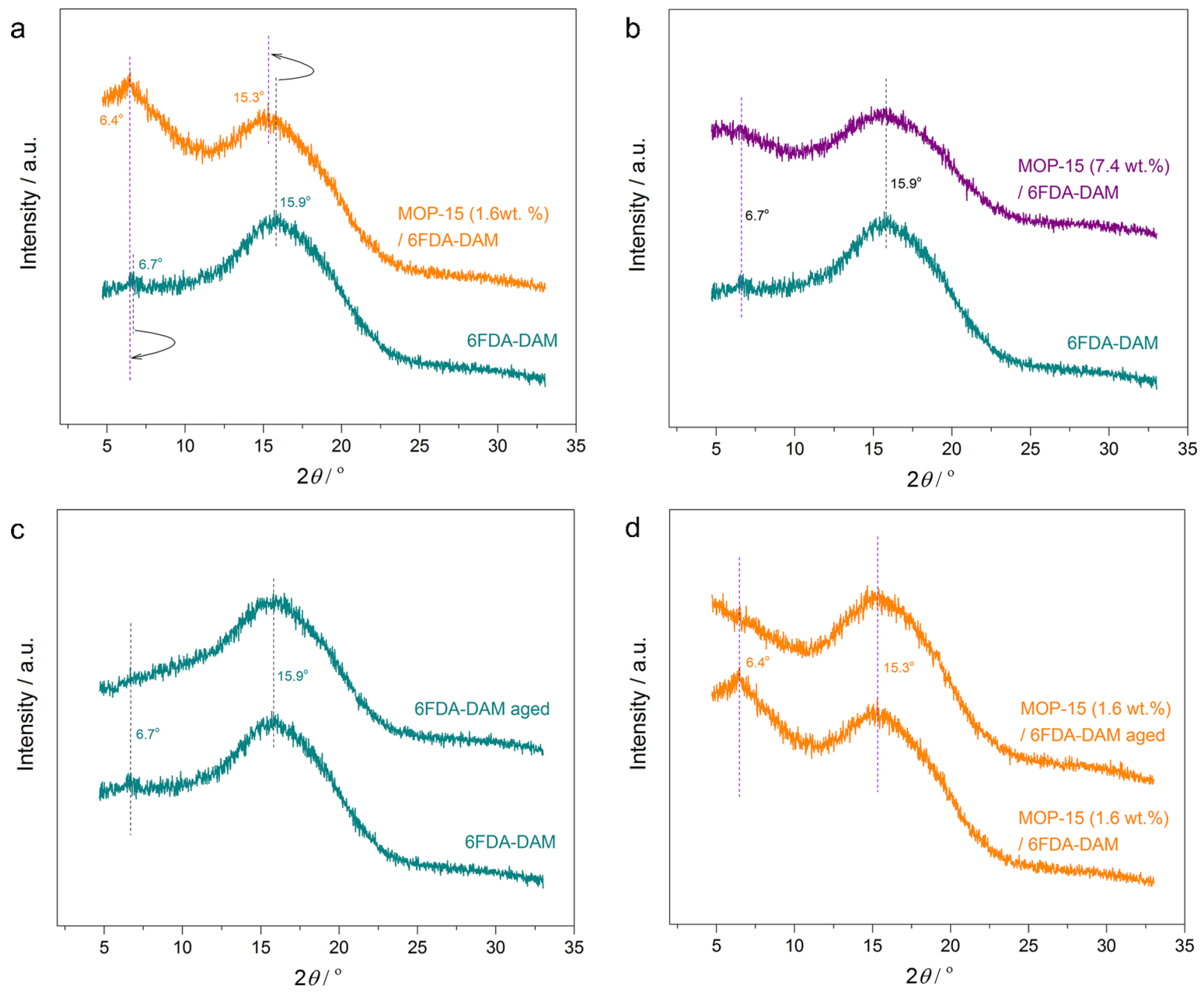

Figure 5. XRD patterns of the fresh and aged (100 days) 6FDA-DAM and MOP-15/6FDA-DAM membranes: (a) fresh 6FDA-DAM and MOP15 (1.6 wt \%)/6FDA-DAM, (b) fresh 6FDA-DAM and MOP-15 (7.4 wt \%)/6FDA-DAM, (c) fresh and aged 6FDA-DAM, and (d) fresh and aged MOP-15 (1.6 wt \%)/6FDA-DAM.

To get further insight into the structure/performance correlation, the $\mathrm{CO}_{2}$ permeability of hybrid membranes was predicted by the Maxwell model (eq 3). ${ }^{1-3}$ The model is strictly applicable to an ideal combination of filler and matrix phases, i.e., diluted suspensions of spherical fillers at low loadings ( $\leq 20 \mathrm{vol} \%$ ) without interfacial defects, aggregations, pore blockages, and rigidification of surrounding polymer chains. ${ }^{1-3}$ As shown in Figure $6 \mathrm{~b}$, the experimental $\mathrm{CO}_{2}$ permeability of the typical hybrid membrane ( 1.8 vol \% or $1.6 \mathrm{wt} \%)$ is much higher than the predicted one even when an ultrafast permeability of MOP-15 fillers is adopted in the model (eq 4). These results indicate that the behavior of the composite membranes is far from ideal blending and suggest that incorporation of the filler changes dramatically the performance (and most likely configuration), as already anticipated from XRD (vide supra). The ultrafine MOP-15 filler (average $9 \mathrm{~nm}$ in diameter) could provide a much higher surface to volume ratio than that of regular MOFs. To achieve an equal external surface area generated from MOP-15 at a filler loading of $1.8 \mathrm{vol} \%, 36 \mathrm{vol} \%$ is required for typical MOFs with a diameter of $180 \mathrm{~nm}$ (Figure 6c). The high external area of
MOP-15 fillers could provide more chance to interact with polymer chains. We speculate that the larger $d$-spacings observed upon doping 6FDA-DAM with small amounts of MOP are largely responsible for this increase in permeability although the MOPs could provide additional pathways, whereas the little increase in selectivity is mostly due to contribution of the filler. Moreover, stabilization of polymer chains should also affect the membrane resistance against aging, as shown below.

Generally, the performance of polymeric membranes is limited by the trade-off defined by the Robeson upper bound. $^{36,38}$ Improvements in permeability are always at the expense of selectivity and vice versa. In the present case, both permeability and selectivity are improved upon 6FDA-DAM doping with MOP-15, bringing membrane performance into the commercial target ${ }^{37}$ for postcombustion $\mathrm{CO}_{2}$ capture (Figure 6f). At varying feed pressure, the hybrid membranes still outperform the ones based on the pure polymer (Figure 6d), with $\mathrm{CO}_{2}$ permeability decreasing gradually with increasing feed pressure (Figure 6d,e) at an almost constant selectivity. The effect of aging was evaluated after keeping the membranes in a desiccator for 100 and 220 days. The results are given in 
a

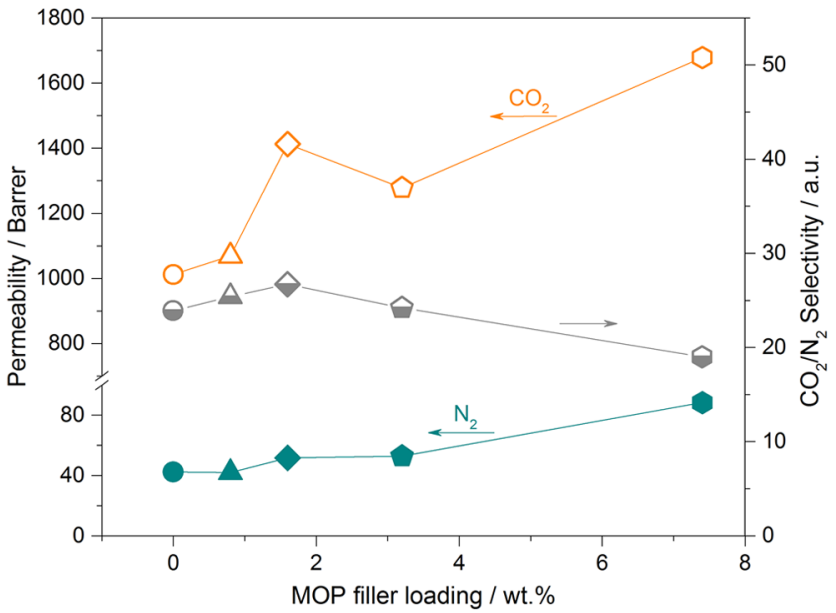

C

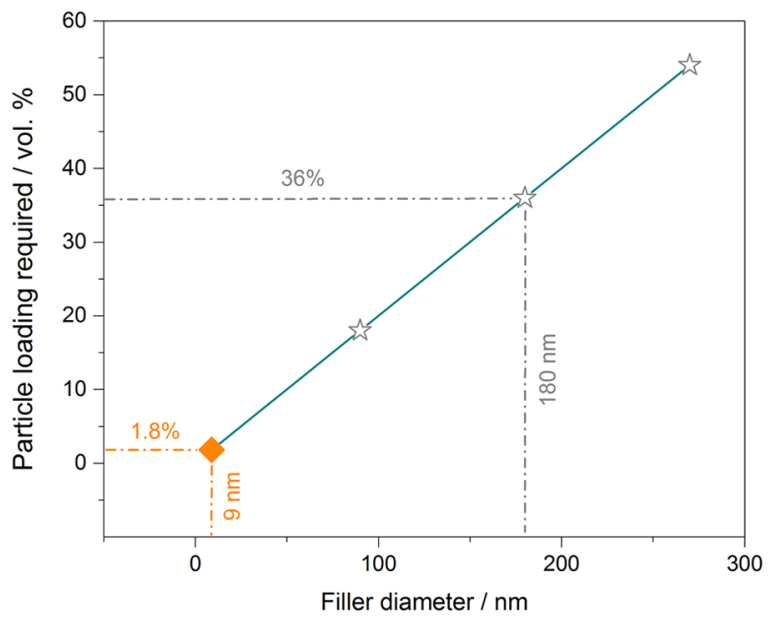

e

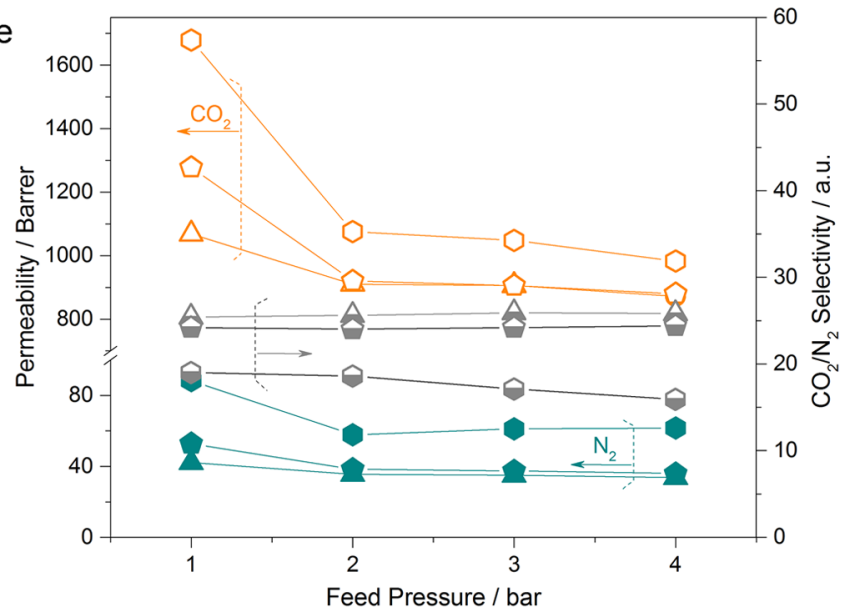

b

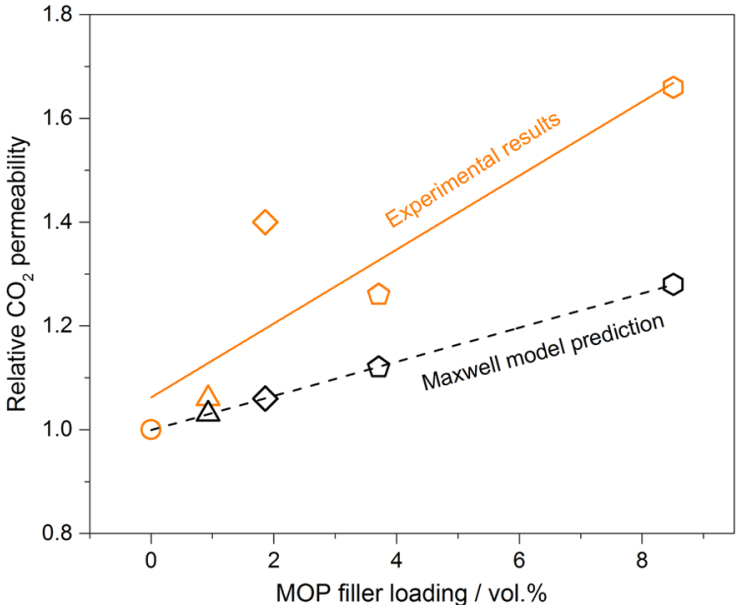

d
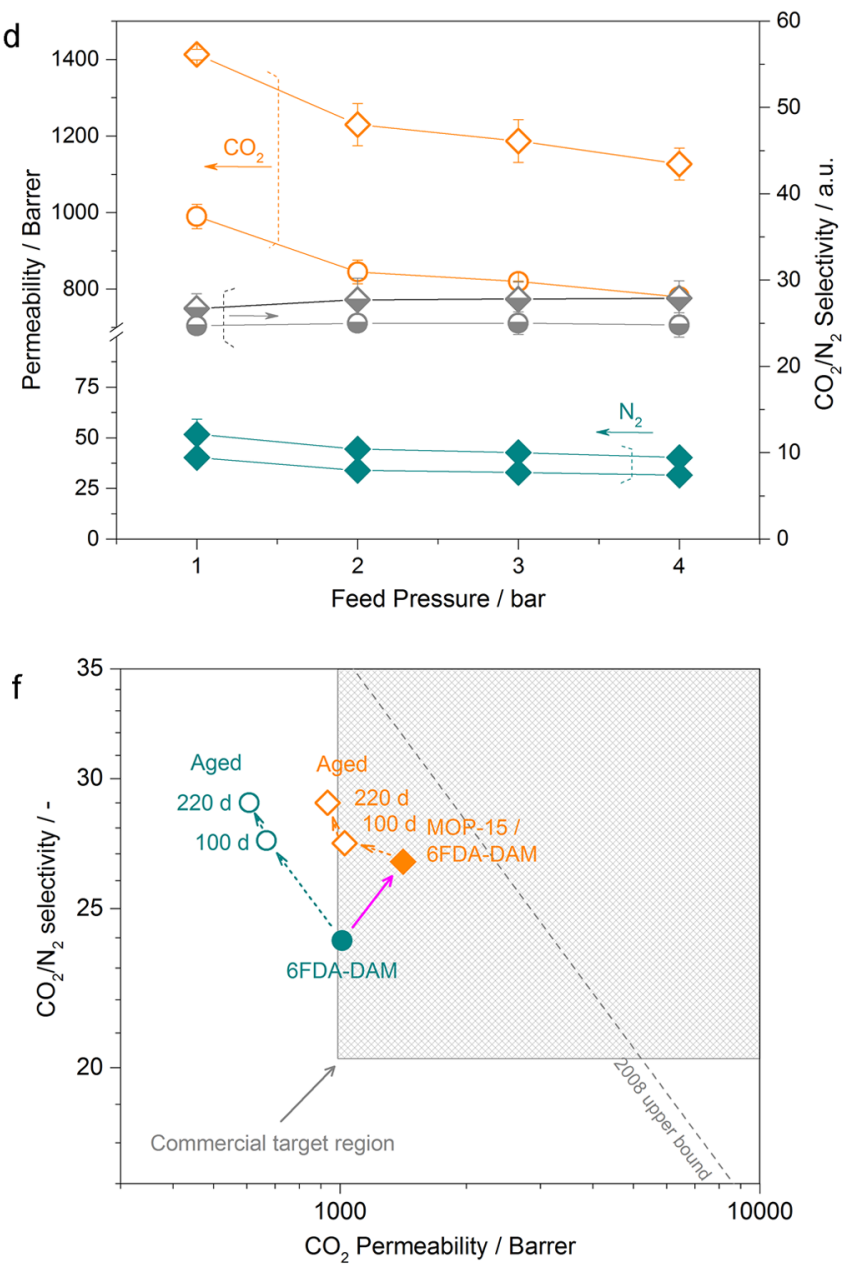

Figure 6. Effect of particle loading ((a, b) 1 bar absolute feed pressure) and feed pressure ((d) 0 and 1.6 wt \% filler loading; (e) 0.8 , 3.2, and 7.4 wt $\%$ filler loading) on the membrane performance: The relative permeability based on the Maxwell model is shown for reference in (b). Open, half open, and solid symbols represent $\mathrm{CO}_{2}$ permeability, selectivity, and $\mathrm{N}_{2}$ permeability, respectively. Circles, triangles, lozenges, pentagons, and hexagons denote the performance of membranes with particle loadings of $0,0.8,1.6,3.2$, and $7.4 \mathrm{wt} \%$, respectively. The volume loading in (b) is calculated based on the corresponding mass loading and material density. Error bars in (d) correspond to standard deviation of duplicate membranes. (c) A plot of particle loading required to provide identical external area vs filler diameter based on eq 5 . (f) $\mathrm{CO}_{2} / \mathrm{N}_{2}$ separation performance of the fresh (solid symbols) and aged (open symbols) membranes at 1 bar absolute feed pressure. The Robeson upper bound (2008) ) $^{36}$ is shown for reference, as well as the commercial target region for $\mathrm{CO}_{2}$ capture from flue gas from Merkel et al. ${ }^{37}$ assuming a membrane thickness of $1 \mu \mathrm{m}$. 1 Barrer $=3.35 \times 10^{-16} \mathrm{~mol} \mathrm{~m} \mathrm{~m}{ }^{-2} \mathrm{~s}^{-1} \mathrm{~Pa}^{-1}$. The feed $\left(15 \mathrm{~mol} \% \mathrm{CO}_{2}\right.$ and $\left.85 \mathrm{~mol} \% \mathrm{~N}_{2}\right)$ temperature was kept constant at $298 \mathrm{~K}$ for all of the permeation measurements.

Figures 6f, S4, and S5. It is well known that during physical aging, the polymer chains of 6FDA-DAM tend to pack more efficiently, ${ }^{39}$ leading to a reduced porosity. The large $d$-spacing corresponding to the diffraction at low angle in the XRD 
patterns was absent after aging (Figure $5 \mathrm{c}, \mathrm{d}$ ). Consequently, a drop in $\mathrm{CO}_{2}$ permeability and a slight increase in selectivity are understandable for the neat and hybrid membranes. Nevertheless, the achieved permeability (934 Barrer) of the aged hybrid membranes (220 days) is still $54 \%$ higher, probably explained by the fact that the $d$-spacing corresponding to the diffraction at high angle was well retained (Figure $5 c, d$ ). The performance of hybrid membrane still meets the commercial target for postcombustion $\mathrm{CO}_{2}$ capture after 100 days of aging.

\section{CONCLUSIONS}

In comparison with MOF-based mixed matrix membranes (Figure S6), which normally reach their optimal performance at a filler loading higher than $10 \mathrm{wt} \%$, the use of MOPs as fillers allows decreasing cargo by 1 order of magnitude while still delivering positive effects on membrane performance in terms of permeability, selectivity, and stability. This effect has been attributed to the molecular size of the MOP-15 filler ( $9 \mathrm{~nm}$ in diameter) that provides a much higher external surface to volume ratio than other fillers. It can be efficiently encapsulated in between polymer chains, modifying in this way polymer packing and increasing permeability and aging resistance. Considering the rapid developments in MOP chemistry, we believe that these molecular materials will offer unrivalled possibilities for the development of mixed matrix membranes.

\section{ASSOCIATED CONTENT}

\section{S Supporting Information}

The Supporting Information is available free of charge on the ACS Publications website at DOI: 10.1021/acsami.8b07045.

Molecular structure, SEM image, adsorption isotherm, and membrane performance (PDF)

\section{AUTHOR INFORMATION}

\section{Corresponding Authors}

*E-mail: x.liu-8@tudelft.nl (X.L.).

*E-mail: jorge.gascon@kaust.edu.sa (J.G.).

\section{ORCID}

Xinlei Liu: 0000-0001-7552-1597

Xuerui Wang: 0000-0003-2220-7531

Liangyong Chu: 0000-0001-7496-4775

Freek Kapteijn: 0000-0003-0575-7953

Jorge Gascon: 0000-0001-7558-7123

\section{Funding}

The authors appreciate the financial support from the European Research Council under the European Union's Seventh Framework Programme (FP/2007-2013), M4CO2 project (608490).

\section{Notes}

The authors declare no competing financial interest.

\section{REFERENCES}

(1) Koros, W. J.; Zhang, C. Materials for next-generation molecularly selective synthetic membranes. Nat. Mater. 2017, 16, 289-297.

(2) Seoane, B.; Coronas, J.; Gascon, I.; Benavides, M. E.; Karvan, O.; Caro, J.; Kapteijn, F.; Gascon, J. Metal-organic framework based mixed matrix membranes: a solution for highly efficient $\mathrm{CO}_{2}$ capture? Chem. Soc. Rev. 2015, 44, 2421-2454.

(3) Merkel, T. C.; Freeman, B. D.; Spontak, R. J.; He, Z.; Pinnau, I.; Meakin, P.; Hill, A. J. Ultrapermeable, reverse-selective nanocomposite membranes. Science 2002, 296, 519-522.
(4) Dechnik, J.; Gascon, J.; Doonan, C. J.; Janiak, C.; Sumby, C. J. Mixed-Matrix Membranes. Angew. Chem., Int. Ed. 2017, 56, 92929310.

(5) Bae, T. H.; Liu, J. Z.; Lee, J. S.; Koros, W. J.; Jones, C. W.; Nair, S. Facile High-Yield Solvothermal Deposition of Inorganic Nanostructures on zeolite crystals for mixed matrix membrane fabrication. J. Am. Chem. Soc. 2009, 131, 14662-14663.

(6) Liu, X. L.; Li, Y. S.; Zhu, G. Q.; Ban, Y. J.; Xu, L. Y.; Yang, W. S. An organophilic pervaporation membrane derived from metal-organic framework nanoparticles for efficient recovery of bio-alcohols. Angew. Chem., Int. Ed. 2011, 50, 10636-10639.

(7) Sabetghadam, A.; Seoane, B.; Keskin, D.; Duim, N.; Rodenas, T.; Shahid, S.; Sorribas, S.; Guillouzer, C. L.; Clet, G.; Tellez, C.; Daturi, M.; Coronas, J.; Kapteijn, F.; Gascon, J. Metal Organic Framework Crystals in Mixed-Matrix Membranes: Impact of the Filler Morphology on the Gas Separation Performance. Adv. Funct. Mater. 2016, 26, 3154-3163.

(8) Rodenas, T.; van Dalen, M.; García-Pérez, E.; Serra-Crespo, P.; Zornoza, B.; Kapteijn, F.; Gascon, J. Visualizing MOF Mixed Matrix Membranes at the Nanoscale: Towards Structure-Performance Relationships in $\mathrm{CO}_{2} / \mathrm{CH}_{4}$ Separation Over $\mathrm{NH}_{2}$-MIL-53(Al)@PI. Adv. Funct. Mater. 2014, 24, 249-256.

(9) Japip, S.; Liao, K. S.; Chung, T. S. Molecularly Tuned Free Volume of Vapor Cross-Linked 6FDA-Durene/ZIF-71 MMMs for $\mathrm{H}_{2} / \mathrm{CO}_{2}$ Separation at $150{ }^{\circ} \mathrm{C}$. Adv. Mater. 2017, 29, No. 1603833.

(10) Lau, C. H.; Nguyen, P. T.; Hill, M. R.; Thornton, A. W.; Konstas, K.; Doherty, C. M.; Mulder, R. J.; Bourgeois, L.; Liu, A. C.; Sprouster, D. J.; Sullivan, J. P.; Bastow, T. J.; Hill, A. J.; Gin, D. L.; Noble, R. D. Ending aging in super glassy polymer membranes. Angew. Chem., Int. Ed. 2014, 53, 5322-5326.

(11) Kang, Z.; Peng, Y.; Qian, Y.; Yuan, D.; Addicoat, M. A.; Heine, T.; Hu, Z.; Tee, L.; Guo, Z.; Zhao, D. Mixed Matrix Membranes (MMMs) Comprising Exfoliated 2D Covalent Organic Frameworks (COFs) for Efficient $\mathrm{CO}_{2}$ Separation. Chem. Mater. 2016, 28, 12771285.

(12) Shan, M.; Seoane, B.; Rozhko, E.; Dikhtiarenko, A.; Clet, G.; Kapteijn, F.; Gascon, J. Azine-Linked Covalent Organic Framework (COF)-Based Mixed-Matrix Membranes for $\mathrm{CO}_{2} / \mathrm{CH}_{4}$ Separation. Chem. - Eur. J. 2016, 22, 14467-14470.

(13) Denny, M. S., Jr.; Moreton, J. C.; Benz, L.; Cohen, S. M. Metalorganic frameworks for membrane-based separations. Nat. Rev. Mater. 2016, 1, No. 16078 .

(14) Wang, Z.; Wang, D.; Zhang, S.; Hu, L.; Jin, J. Interfacial Design of Mixed Matrix Membranes for Improved Gas Separation Performance. Adv. Mater. 2016, 28, 3399-3405.

(15) Xiang, L.; Sheng, L.; Wang, C.; Zhang, L.; Pan, Y.; Li, Y. AminoFunctionalized ZIF-7 Nanocrystals: Improved Intrinsic Separation Ability and Interfacial Compatibility in Mixed-Matrix Membranes for $\mathrm{CO}_{2} / \mathrm{CH}_{4}$ Separation. Adv. Mater. 2017, 29, No. 1606999.

(16) Rodenas, T.; Luz, I.; Prieto, G.; Seoane, B.; Miro, H.; Corma, A.; Kapteijn, F.; Llabres, I. X. F. X.; Gascon, J. Metal-organic framework nanosheets in polymer composite materials for gas separation. Nat. Mater. 2015, 14, 48-55.

(17) Ghalei, B.; Sakurai, K.; Kinoshita, Y.; Wakimoto, K.; Isfahani, A. P.; Song, Q.; Doitomi, K.; Furukawa, S.; Hirao, H.; Kusuda, H.; Kitagawa, S.; Sivaniah, E. Enhanced selectivity in mixed matrix membranes for $\mathrm{CO}_{2}$ capture through efficient dispersion of aminefunctionalized MOF nanoparticles. Nat. Energy 2017, 2, 17086.

(18) Bae, T. H.; Lee, J. S.; Qiu, W.; Koros, W. J.; Jones, C. W.; Nair, $\mathrm{S}$. A high-performance gas-separation membrane containing submicrometer-sized metal-organic framework crystals. Angew. Chem., Int. Ed. 2010, 49, 9863-9866.

(19) Bachman, J. E.; Smith, Z. P.; Li, T.; Xu, T.; Long, J. R. Enhanced ethylene separation and plasticization resistance in polymer membranes incorporating metal-organic framework nanocrystals. Nat. Mater. 2016, 15, 845-849.

(20) Takeda, N.; Umemoto, K.; Yamaguchi, K.; Fujita, M. A nanometre-sized hexahedral coordination capsule assembled from 24 components. Nature 1999, 398, 794-796. 
(21) Olenyuk, B.; Whiteford, J. A.; Fechtenkotter, A.; Stang, P. J. Selfassembly of nanoscale cuboctahedra by coordination chemistry. Nature 1999, 398, 796-799.

(22) Eddaoudi, M.; Kim, J.; Wachter, J. B.; Chae, H. K.; O’Keeffe, M.; Yaghi, O. M. Porous Metal-Organic Polyhedra $25 \AA$ A Cuboctahedron Constructed. J. Am. Chem. Soc. 2001, 123, 4368-4369.

(23) Li, J. R.; Zhou, H. C. Bridging-ligand-substitution strategy for the preparation of metal-organic polyhedra. Nat. Chem. 2010, 2, 893898.

(24) Vardhan, H.; Yusubov, M.; Verpoort, F. Self-assembled metalorganic polyhedra: An overview of various applications. Coord. Chem. Rev. 2016, 306, 171-194.

(25) Perez, E. V.; Balkus, K. J.; Ferraris, J. P.; Musselman, I. H. Metalorganic polyhedra 18 mixed-matrix membranes for gas separation. $J$. Membr. Sci. 2014, 463, 82-93.

(26) Zhao, C.; Wang, N.; Wang, L.; Huang, H.; Zhang, R.; Yang, F.; Xie, Y.; Ji, S.; Li, J. R. Hybrid membranes of metal-organic molecule nanocages for aromatic/aliphatic hydrocarbon separation by pervaporation. Chem. Commun. 2014, 50, 13921-13923.

(27) Ma, J.; Ying, Y.; Yang, Q.; Ban, Y.; Huang, H.; Guo, X.; Xiao, Y.; Liu, D.; Li, Y.; Yang, W.; Zhong, C. Mixed-matrix membranes containing functionalized porous metal-organic polyhedrons for the effective separation of $\mathrm{CO}_{2}-\mathrm{CH}_{4}$ mixture. Chem. Commun. 2015, 51, $4249-4251$.

(28) Kitchin, M.; Teo, J.; Konstas, K.; Lau, C. H.; Sumby, C. J.; Thornton, A. W.; Doonan, C. J.; Hill, M. R. AIMs: a new strategy to control physical aging and gas transport in mixed-matrix membranes. $J$. Mater. Chem. A 2015, 3, 15241-15247.

(29) Bushell, A. F.; Budd, P. M.; Attfield, M. P.; Jones, J. T.; Hasell, T.; Cooper, A. I.; Bernardo, P.; Bazzarelli, F.; Clarizia, G.; Jansen, J. C. Nanoporous organic polymer/cage composite membranes. Angew. Chem., Int. Ed. 2013, 52, 1253-1256.

(30) Mao, H.; Zhang, S. Mixed-matrix membranes incorporated with porous shape-persistent organic cages for gas separation. J. Colloid Interface Sci. 2017, 490, 29-36.

(31) Furukawa, H.; Kim, J.; Ockwig, N. W.; O’Keeffe, M.; Yaghi, O. M. Control of Vertex Geometry, Structure Dimensionality, Functionality, and Pore Metrics in the Reticular Synthesis of Crystalline MetalOrganic Frameworks and Polyhedra. J. Am. Chem. Soc. 2008, 130, 11650-11661.

(32) Maxwell, J. C. Treatise on Electricity and Magnetism. Oxford University Press: London, 1873.

(33) Boom, J. R. Transport through Zeolite-Filled Polymeric Membranes. Ph.D. thesis, University of Twente, 1994.

(34) Etxeberria-Benavides, M.; David, O.; Johnson, T.; Łozińska, M. M.; Orsi, A.; Wright, P. A.; Mastel, S.; Hillenbrand, R.; Kapteijn, F.; Gascon, J. High performance mixed matrix membranes (MMMs) composed of ZIF-94 filler and 6FDA-DAM polymer. J. Membr. Sci. 2018, 550, 198-207.

(35) Sabetghadam, A.; Liu, X.; Benzaqui, M.; Gkaniatsou, E.; Orsi, A.; Lozinska, M. M.; Sicard, C.; Johnson, T.; Steunou, N.; Wright, P. A.; Serre, C.; Gascon, J.; Kapteijn, F. Influence of Filler Pore Structure and Polymer on the Performance of MOF-based Mixed Matrix Membranes for $\mathrm{CO}_{2}$ Capture. Chem. - Eur. J. 2018, 24, 7949-7956.

(36) Robeson, L. M. The upper bound revisited. J. Membr. Sci. 2008, 320, 390-400.

(37) Merkel, T. C.; Lin, H.; Wei, X.; Baker, R. Power plant postcombustion carbon dioxide capture: An opportunity for membranes. J. Membr. Sci. 2010, 359, 126-139.

(38) Park, H. B.; Kamcev, J.; Robeson, L. M.; Elimelech, M.; Freeman, B. D. Maximizing the right stuff: The trade-off between membrane permeability and selectivity. Science 2017, 356, No. eab0530.

(39) Cui, L.; Qiu, W.; Paul, D. R.; Koros, W. J. Physical aging of 6FDA-based polyimide membranes monitored by gas permeability. Polymer 2011, 52, 3374-3380. 